\section{Feiras livres: (re)apropriação do território na/da cidade, neste período técnico-científico-informacional}

José Erimar dos santos*
Resumo: Objetiva-se refletir sobre feira livre, enfocando sua importância na cidade, que se apresenta cada vez mais competitiva e fragmentada, do ponto de vista da (re)apropriação do território. Entendido aqui como um suporte essencial, no que diz respeito à manutenção e busca das estratégias de reprodução das relações socioespaciais, o território, para os feirantes, é analisado mediante a existência e manutenção das atividades feiras livres, como é o caso da Feira da Pedra, em São Bento (PB), recorte espacial empírico deste trabalho. Sendo locais apropriados coletivamente, as feiras livres significam o lócus em que é fato as distintas territorialidades que implicam também na (re)produção do espaço urbano, inseridas no circuito inferior da economia urbana, das cidades onde ocorrem..

\section{Open fairs: (re)appropriation of the territory in/of the city, this period technical-cientific-informational}

\footnotetext{
Abstract: The objective is to reflect on open fair, focusing on its importance in the city, which appears increasingly competitive and fragmented, in terms of (re)appropriation of the territory. Understood here as essential support, with respect to maintenance and playback search strategies sociospatial relations, the territory for the marketer, is analyzed by the existence and activity maintenance fairs, such as of Feira da Pedra in the São Bento (PB), spatial area of empirical work. As appropriate locations collectively, the open fairs mean that the locus is the fact that distinct territoriality also involves the (re) production of urban space, inserted in the circuit of the urban economy, in the cities where its occur.
}

${ }^{*}$ Doutorando do Programa de Pós-Graduação e Pesquisa em Geografia pela Universidade Federal do Rio Grande do Norte/UFRN, Brasil

Palavras-chave: Território; Feiras livres; Feirantes; Cidade; Feira da Pedra

Key-Words: Territory; Open fairs; Marketer; City; Feira da Pedra 
1- Vale ressaltar que não se quer aqui adjetivar as feiras livres de atividades não-modernas, uma vez que as mesmas são (re) apropriadas pelas dinâmicas

do capital ao longo do

tempo e transformadas

por este. Nem tão pouco afirmar que toda feira livre é produto do circuito inferior

da economia urbana, haja vista diversas feiras livres no

Brasil terem sido, ao longo do tempo, se transformado em atrativos turísticos, vendendo produtos

diferenciados dos que até então comercializavam e com a presença de consumidores e dinâmica de altos rendimentos. Veja, por exemplo, a Feira de Caruaru (PE), a Feira do Ver-o-Peso, localizadas às margens da Baía do Guajará, em Belém (PA), dentre outras.

2- Hoje, mediante a crescente interdependência entre os lugares e a rapidez com que os eventos ocorrem

é evidente a dificuldade

de notar e/ou identificar em diversas cidades esses

setores, haja vista uma grande parcela da população pertencente à classe média aí se fazerem presentes. Assim, existindo cidades com essas características no rol dos países subdesenvolvidos ou em desenvolvimento ou países subdesenvolvidos industrializados, torna-se dificultoso encontra-se ares primitivas, tradicionais, mesmo quando esses termos se referem a sinônimos históricos, pois.

Geografia Ensino \& Pesquisa, v. 17 , n. 2 p. $39-56$, mai./ago..

Feiras Livres: (Re) Apropriação do território na/da cidade, neste período Técnico-CientíficoInformacional

\section{Introdução}

Neste período técnico-científico-informacional, tempo atual do espaço geográfico, cuja natureza é técnica, científica e informacional, conforme Santos (1994; 2008a; 2005; 2009a) e Santos e Silveira (2002), o meio geográfico resultante e de mesmo nome, produz-se da intensidade, em sua estrutura, da aplicação da tecnologia, da ciência e da informação no processo produtivo.

Para Santos (2005, p. 121), a partir do final da Segunda Guerra Mundial “o território vai se mostrando cada dia que passa com um conteúdo maior em ciência, em tecnologia e em informação". Segundo ele, a componente informação é quem vai ser, nesse período, o grande regedor das ações que definem novas realidades espaciais, dando ao meio e aos seus objetos e ações uma organização típica desse processo. Assim, o meio técnico-científico-informacional é, portanto, "um meio geográfico onde o território inclui obrigatoriamente ciência, tecnologia e informação" (SANTOS, 2008a, p. 41), resultante do período/tempo de mesmo nome.

Sendo seus efeitos materializados em objetos e ações, por um lado modernos e por outro lado, aqueles não-modernos, mas resultantes de um mesmo processo-o desenvolvimento do capital -, tanto no espaço urbano como, atualmente, no rural, fez/faz uma massa muito grande de pessoas a serem sujeitos do espaço geográfico (aqui frisado a escala urbana) atuante dos processos de (re)produção socioespacial. Essa massa, juntamente com as atividades que realizam constitui aquilo que Santos (1979) chamou de circuito inferior da economia urbana, do qual a atividade feira livre é representativa, conforme Santos (2012). Nesse sentido, a coexistência, no espaço, dos empreendimentos modernos, chamados de circuito superior da economia urbana, ao lado dos "não-modernos", como as feiras livres pode ser muito bem entendida mediante a teoria dos dois circuitos da economia urbana: o circuito superior e circuito inferior (SANTOS, 1979) ${ }^{1}$.

Em outras palavras, independente do nível de crescimento, a maioria das cidades possuem duas áreas de mercado, uma representada pela realidade "nova", "moderna" e outra com gostos "tradicionais", "primitivos", que podem ser facilmente identificados, pois estes dois subsistemas econômicos atuam lado a lado, de forma complementar².

Evidentemente que quando Milton Santos escreve sobre o que ele chamou de circuito superior e circuito inferior o sistema capitalista ainda não havia se projetado no espaço geográfico da maneira como se encontra nos dias atuais, pois ainda não eram tão presentes, na configuração do espaço geográfico dos elementos: informação, tecnologia e ciência como suporte do capital. Os processos eram outros, já que o espaço vivia outro momento. Sendo subsistemas da economia urbana interligados, reporta-se, nas condições atuais de aceleração do capitalismo, ao circuito superior como exclusivamente povoado do grande capital ou do capital moderno é temeroso, pois existe uma mistura muito intensa desses subsistemas, no sentido de que existe muito do circuito inferior no circuito superior. Veja-se o exemplo dos grandes investidores em redes hoteleiras de luxo ou lojas de luxo, que se encontram em diversas cidades brasileiras, cujos capitais provém do comércio ilícito e/ ou de comercialização de produtos falsificados, angariados dentro de formas comerciais do chamado circuito inferior.

Dentro dessa realidade de período e meio $^{3}$ técnico-científico-informacional, muito embora não necessariamente na perspectiva dos circuitos da economia urbana e nem também na linha desse período, diversos esforços foram feitos no sentido de trazer para a discussão, o espaço urbano, recorte empírico e também teórico, onde é mais notório os circuitos da economia e a configuração socioespacial desse período do espaço geográfico. É o caso de autores como Corrêa (1995); Trindade Jr. (1998); Sena (2002), dentre outros, que de uma maneira ou de outra explicitam fatos referentes à expansão urbana, à segregação socioespacial, às questões de moradia à qualidade de vida, sobretudo nas cidades grandes, mas que existem 
também em cidades menores.

Diante disto, este trabalho objetiva refletir sobre feira livre, enfocando sua importância na contemporaneidade, enfatizando a (re)apropriação do território por parte dos sujeitos feirantes no processo de realização dessa atividade. Não obstante é, pois, o conceito de território o elemento central dessa análise, no sentido de que as práticas socioespaciais verificadas nessa atividade tendem a projetar sobre o espaço (conforme aqui já especificado o urbano) relações de poder, definidoras de (re)apropriação territorial mediante seus sujeitos socioespaciais e suas atividades comerciais.

Como referência empírica, este artigo traz a Feira da Pedra realizada todas as segundasfeiras, em São Bento, cidade paraibana localizada na Região Nordeste do Brasil (figura 1).

Figura 1 - São Bento: localização geográfica em relação ao Brasil e região Nordeste: destaque para seus limites municipais

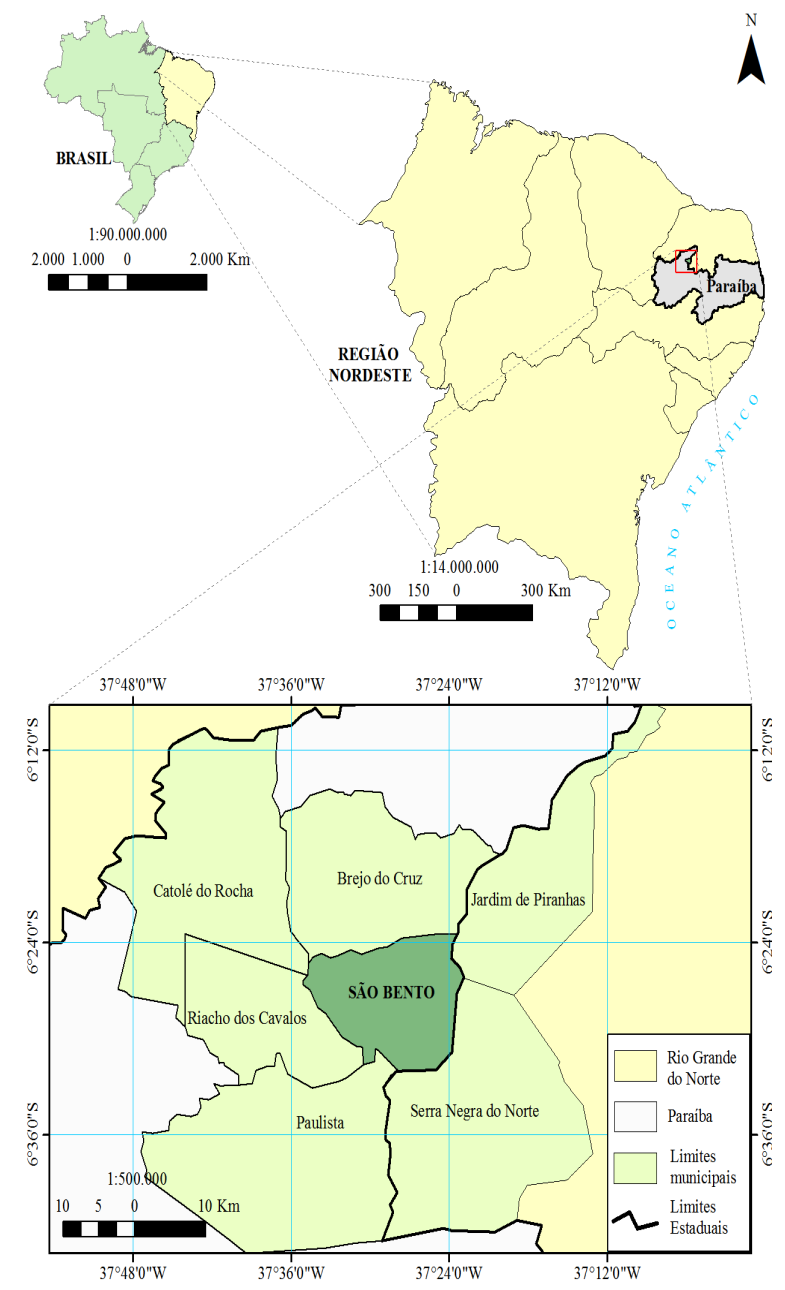

Fonte: Santos (2012, p. 24).

Sendo uma manifestação das especificidades da economia urbana daquela cidade paraibana na sua relação com outros lugares. Toma-se este local como uma possibilidade de analisar formas de (re)apropriação coletiva, em que os aspectos econômicos, a priori, transcendem em termos de significados e importância para a vida naquela cidade e município em particular, e, região, ao qual forma esta atividade no seu processo de realização congregando espaços urbanos e rurais diversos da Região Nordeste. Dessa forma, a Feira da Pedra bem como as feiras livres de um modo geral possuem elementos e características passíveis de uma leitura geográfica no âmbito da compreensão dos espaços apropriados, no sentido de haver os
2 (cont.)- a função e os processos são outros, embora a forma seja a mesma mediante uma estrutura que se (re) organiza e se transforma a cada instante, momento do espaço geográfico

3- Toda vez que neste trabalho aparecer a palavra período e meio técnicocientífico-informacional leva-se em consideração o aspecto temporal do espaço (período) e a realidade material e dinâmica que o se configura nos lugares (meio).
Geografia Ensino \& Pesquisa, v 17, n.2 p. 39-56, mai./ago. 2013

Santos, J.E. 
feirantes disputando entre si e/ou com o poder público municipal, territórios, buscando sua (re)afirmação no contexto de produção do espaço urbano frente esse período e meio técnicocientífico-informacional.

Ademais, realiza-se uma rápida abordagem da formação das feiras livres em diversos espaços e tempos, enfatizando a Feira da Pedra no contexto geográfico da cidade de São Bento. Em seguida, será debatido o conceito de território e feira livre, pensando a (re)produção socioespacial a partir do espaço citadino, destacando nesse processo ainda a importância que a Feira da Pedra em São Bento assume nesse período e meio técnico-científico-informacional, levando em consideração o seu papel estratégico/geopolítico para os produtores têxteis de fabricação de redes de dormir existentes no município de São Bento e região de entorno, fato que fortalece ainda mais as territorialidades ali existentes no contexto da economia urbana da cidade. Por fim, aborda-se a ação do Estado, no sentido de poder público frente políticas de ordenamento e gestão do espaço urbano, em que se destaca o caso da Avenida Francisco de Paula Saldanha e o Mercado das Redes, espaços públicos onde se realiza a Feira da Pedra e para onde será transferida, respectivamente.

\section{As feiras livres numa perspectiva geohistórica: trazendo a questão da Feira da Pedra, em São Bento (PB)}

Uma das referências mais antigas que podemos inferir sobre feiras ou mercados encontra-se em Mumford $(1998$, p. 85), quando este constata que antes de Cristo elas já existiam. Assim, “[...] as duas formas clássicas de mercado, a praça aberta ou o bazar coberto, e a rua de barracas ou de lojas, possivelmente já tinham encontrado sua configuração urbana por volta de 2000 a.C., a mais tarde". Afirma ainda que elas foram "[...] precedidas pela forma ainda mais antiga do supermercado - dentro do recinto do templo", pois, nesse período, os templos serviam não somente de locais do deus e dos sacerdotes, mas também onde os bens agrícolas e industriais sofriam a tributação antes de circularem, o que ocorre de maneira distinta no início da era cristã da sociedade humana, onde o templo chegou a servir também de mercado, conforme percebe-se na Bíblia Sagrada.

É aquela passagem bíblica do evangelista João, capítulo 2, do versículo 13 ao 17, a primeira referência de feira depois de Cristo - d.C. Citando a proximidade da páscoa dos judeus, e a subida de Jesus Cristo para a cidade de Jerusalém, onde ao entrar no templo, "[...] encontrou os vendedores de bois, ovelhas e pombas, e os cambistas sentados" no Templo de Jerusalém, o narrador desse Evangelho dar elementos de indução de que ali, naquele momento, se realizava uma feira e/ou uma atividade comercial típica do mercado. Assim, esses fenômenos econômicos, sociais e espaciais - as feiras - não são tão recentes nos espaços urbanos.

No Brasil, elas são uma realidade e envolvem significativos fluxos de mercadorias, pessoas e informações, integrando áreas rurais, e pequenas, médias e grandes cidades, manifestando uma atividade ainda hoje importante para muitos sujeitos urbanos e rurais.

Analisando o Brasil do século XVII ao XIX, como um espaço compreendido

Geografia Ensino \& Pesquisa, v. 17 , n.2 p. $39-56$, mai./ago..

Feiras Livres: (Re) Apropriação do território na/da cidade, neste período Técnico-CientíficoInformacional ISSN 2236-4994 essencialmente de duas "zonas ativas", a zona "da Bahia a Santos", onde se verificavam as "plantações, [...] tais como o açúcar, o café, o cacau, o algodão" e a zona interior, "mineradora" (DEFFONTAINES, 1945, p. 42), evidencia a importância das feiras de burros da cidade paulista de Sorocaba para a dinâmica desse espaço, no período estudado - final da primeira metade do século passado.

Olmária Guimarães, discutindo a importância das feiras livres para o abastecimento de alimentos na cidade de São Paulo, afirma: "é importantíssima a participação das feiras-livres na distribuição de gêneros alimentícios ao consumidor, mesmo porque a sua clientela é das mais variadas, no tocante às classes sociais" (GUIMARÃES, 1969, p. 15). Essa autora chama a atenção ainda para o que seriam os protótipos das feiras livres: as quitandas - " [...] uma espécie 
de mercado ou feira, senão a própria praça, a rua, o lugar determinado à venda de produtos da terra" (GUIMARÃES, 1969, p. 21). Ou seja, as quitandas eram "aglomerações de negras ao ar livre, ancoradas ou dispondo de tabuleiros, situadas em pontos preestabelecidos, para a venda de produtos da pequena lavoura, da pesca e da indústria doméstica” (JESUS, 2009, p. 165).

Para Mott (1975), antes dos europeus chegarem ao Brasil, já existiam trocas entre os nativos, e, dissertando sobre as trocas daqueles com estes, afirma que os "produtos eram trazidos pelos silvícolas até a praia e entregues nas mãos de particulares ou nas feitorias, a fim de serem embarcados para o Reino quando da chegada das naus" (MOT'T, 1975, p. 308). Evidentemente que não se pode chamar essa forma de comércio de feira, mas pode-se pensar, a partir daí, no estabelecimento dessa atividade comercial periódica no Brasil, implantada pelos colonizadores portugueses, tendo surgido devido ao aumento da população e também à diversificação econômica. Segundo esse autor, a primeira referência de feira no Brasil data de 1548, quando no Regimento enviado ao Governador Geral, o rei Dom João III, ordenava "que nas ditas vilas e povoados se faça em um dia de cada semana, ou mais, se vos parecerem necessários, feira [...]” (MOTT, 1975, p. 309). Vale ressaltar que, já tendo experiência com feiras, aos portugueses não interessavam abastecer a população local, mas sim explorá-la, através da reunião dos produtos que eram expostos pelos nativos.

Gilmar M. de Jesus, objetivando estudar o lugar da feira livre na grande cidade capitalista, no caso o Rio de Janeiro, no período de 1964 a 1989, mostra que essa atividade já foi "responsável pela distribuição da maior parte dos hortigranjeiros, frutas e pescado consumidos diariamente pela população carioca, superando nestes setores todas as demais formas de varejo somadas: supermercados, quitandas, peixarias [...]" (JESUS, 1992, p. 95). Tal estudo reflete a importância dessa atividade periódica de comércio, sobretudo no abastecimento hortifrutigranjeiro da "cidade maravilhosa", no período mencionado.

Assim sendo, em várias cidades brasileiras, as feiras são o principal local de comércio da população, principalmente no Nordeste, onde se constitui "em um tipo particular de mercado periódico" (CORRÊA, 2001, p. 113). Segundo esse mesmo autor, os mercados periódicos são um dos modos de organização da rede de localidades centrais em países subdesenvolvidos, definindo-os como:

[...] aqueles núcleos de povoamento, pequenos, via de regra, que periodicamente se transformam em localidades centrais [...]. Fora dos períodos de intenso movimento comercial, esses núcleos voltam a ser pacatos núcleos rurais, com a maior parte da população engajada em atividades primárias (CORRÊA, 2001, p. 50).

Nesse período técnico-científico-informacional, em função de uma economia cada vez mais centrada nos serviços, aqueles "núcleos de povoamento pequenos" apontados pelo autor acima, não se centram mais, sobretudo a maioria de sua população, "em atividades primárias", uma vez que há uma dinamicidade resultante de fatores/atividades econômicas diversas, quando não se faz presente a feira nesses pequenos povoados. Atividades essas ligadas ao circuito inferior da economia urbana dessas pequenas aglomerações urbanas. Nesses núcleos de povoamento pequenos existem diversos pontos comerciais, o que faz com que grande parte da população dos mesmos esteja a elas engajados e não somente a sua maioria ligada a atividades econômicas. Isso é notório quando se percebe a diversidade intra-regional que existe, sobretudo no Brasil e em especial no Nordeste brasileiro.

No Nordeste, essa modalidade periódica de comércio varejista (a feira livre) conseguiu maior êxito em função, principalmente, da própria formação econômica e socioespacial da região, que envolve, dentre outros, os meios de comunicação existentes, o tipo de agricultura e pecuária praticado (ANDRADE, 1986; 1987). Nessa região, a feira livre desempenhou e desempenha uma grande importância por ser uma das principais formas de comercialização da produção agrícola e principal comércio varejista de abastecimento para uma parcela considerável da população, como é representativo a Feira da Pedra em São Bento, com seus produtos têxteis (redes de dormir, toalhas, panos de prato, fios, cobertas, conjuntos para

Geografia Ensino \& Pesquisa, v. 17, n.2 p. 39-56, mai./ago. 2013

Santos, J.E. 
banheiros e cozinhas, tapetes etc., (Figura 2). Assim, foi o intenso comércio de gado verificado nessa região, nos séculos XVIII e XIX; justificado pelo afastamento do gado das regiões litorâneas canavieiras, que, nesse processo, fixava o homem, a causa da origem das feiras nessa região.

Figura 2 - Aspecto geral da Feira da Pedra em São Bento (PB)

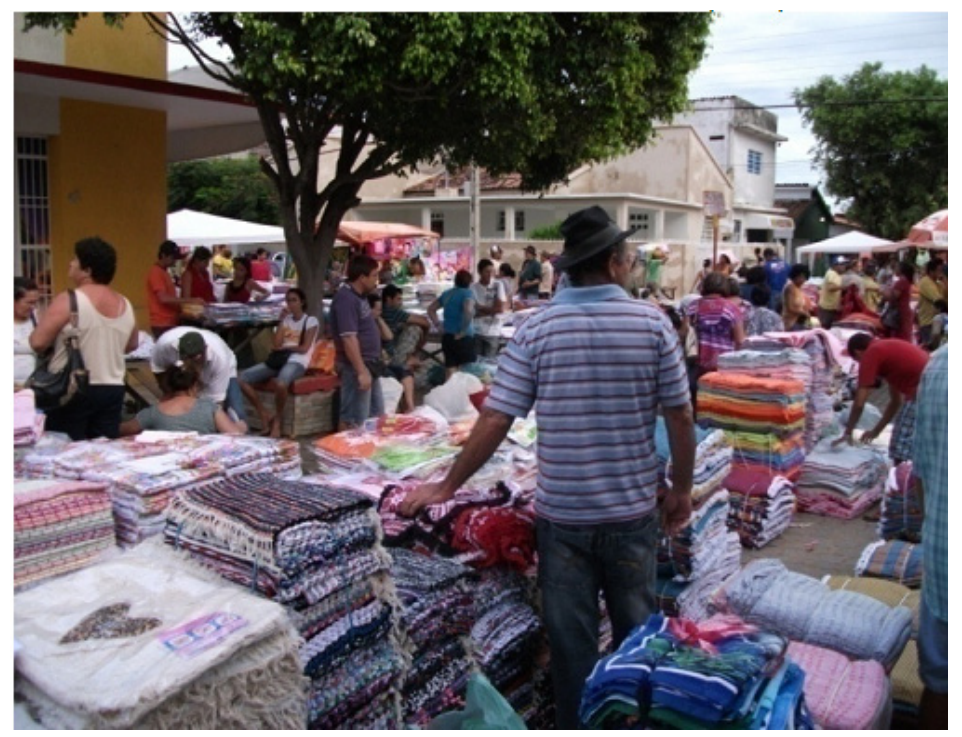

Fonte: Santos, (2012, p. 133).

Vale ressaltar, ainda, que uma das características das feiras no Nordeste era o artesanato, que constituía um ponto fundamental desses comércios periódicos. Era muito "comum encontrar o artesão em plena atividade, fabricando principalmente os artefatos de couro, como sandálias, alpercatas e calçados" (PAZERA JR., 2003, p. 29).

Todavia, um tipo específico de produto resultante da atividade artesanal, a rede de dormir, hoje ainda se faz presente nas feiras de algumas cidades nordestinas, como é o caso de São Bento, na Paraíba. Produto este bastante aceito pela clientela que a esta cidade se dirige em busca dessa mercadoria e de outras, que são fabricadas pela indústria têxtil local e regional, encontrando na Feira da Pedra um local para a aquisição dos mesmos. As redes de dormir possuem preços mais acessíveis que as camas, bem como são mais fáceis de serem transportadas, conforme já havia observado Cascudo (2003) e, hoje, ainda são muito consumidas. Em São Bento, a produção de redes de dormir é responsável, em parte, pela sua configuração socioterritorial e pela permanência da Feira da Pedra, que tem, na cultura algodoeira - embora pouco expressiva no Nordeste, nesse meio e período técnicos, científicos e informacionais -, a matriz de uma geografia e geograficidade ímpar. Dessa forma, na Feira da Pedra comercializam-se redes de dormir, panos de prato, tapetes, dentre outros produtos

Geografia Ensino \& Pesquisa, v. 17, n.2 p. $39-56$, mai./ago.

Feiras Livres: (Re) Apropriação do território na/da cidade, neste período Técnico-CientíficoInformacional que têm na sua base, de forma indireta, a matéria-prima algodão e, de forma direta, a indústria têxtil, local e regional, de redes de dormir e seus derivados.

A origem e a existência da Feira da Pedra no espaço urbano de São Bento devem-se a diversos fatores, quais sejam: a) ao potencial do lugar (diz respeito ao volume de mercadorias têxteis que são produzidas no lugar); b) à acessibilidade (rodovias, pontes, e os diferentes meios de transportes - moto, carros, bicicleta etc.); c) ao crescimento da atividade industrial têxtil (presença cada vez mais intensa de equipamentos técnicos mais sofisticados para o fabrico de mercadorias têxteis); d) à intersecção de produtos têxteis (nas vizinhanças de São Bento se localizam cidades que produzem mercadorias têxteis e levam até essa cidade suas mercadorias para comercializarem na Feira da Pedra); e, ainda, e) à ausência de pagamento de imposto ao 
poder público local. Tudo isso, somando-se e sendo consequência sobremaneira do surgimento da atividade industrial têxtil nessa cidade e das mudanças sociais, políticas, culturais e técnicas, resulta na origem e existência da Feira da Pedra, que será melhor compreendida mediante sua relação com a (re)produção socioespacial são-bentense, o que se faz necessário pensar-se na relação entre feira livre e território.

\section{Território e feira livre}

Existindo no espaço urbano, as feiras livres chamam às autoridades urbanas a se empenharem em sua organização e vigilância, pois é comum a presença, muitas vezes, do fiscal da prefeitura, policiais, em meio aos feirantes e consumidores etc. Com efeito, "seja como for, intermitentes ou contínuos, esses mercados elementares entre campo e cidade, pelo seu número e incansável repetição, representam a mais volumosa de todas as trocas conhecidas" (BRAUDEL, 1996, p. 16), sendo de certa forma, um território urbano no/do urbano.

Nesse período técnico-científico-informacional, as cidades vêm passando por uma dinâmica bastante complexa, fato que interfere na imagem que se tem da cidade moderna. Conforme Carlos (1997), a criação dessa nova urbanidade confunde-se com um tempo mais rápido, cujas transformações na maneira de se relacionar e produzir no espaço chegam a ser uma condição específica da cidade, mas que repercute no campo também. Assim, no atual período do espaço existe uma produção intensa de novas representações do urbano, bem como uma extrema valorização do social, do grupo, do coletivo, no sentido de os homens buscarem cada vez mais viverem em aglomerados.

Sabe-se que a maneira pela qual os diferentes grupos sociais participam da produção do espaço urbano é distinta. Mas conscientes ou inconscientes os grupos sociais veem a cidade, cada vez mais como um espaço de possibilidades. Isto é, os objetos e as ações representativas do cotidiano de um grupo social manifestam-se mediante um jogo de forças travado entre os outros representantes da coletividade urbana (SANTOS, 2009a; CORRÊA, 1995). Diante disso, as possibilidades transformam-se e significam a manifestação de diferentes territorialidades (SAQUET, 2007), diferentes formas de (co)agir, num mesmo território.

De igual modo como é a cidade, marcada pela enorme demanda de reivindicações colocadas pelos diferentes grupos sociais urbanos, apresentando-se como um campo de forças, no qual diferentes interesses passam a lutar, simultaneamente, pelo direito à mesma (LEFEBVRE, 2001), também são as feiras, um espaço marcado por diferentes recortes territoriais. De fato, assim como a grande, média ou pequena cidade não pode ser entendida como um espaço homogêneo, as feiras assim também não podem. Uma visão mais acurada dessas duas realidades, ou melhor, desses dois territórios, refletirá a complexidade de relações materiais e imateriais que os cercam.

As grandes transformações ocorridas não apenas nas grandes cidades, mas, sobretudo nestas, no atual período do espaço, acabam reforçando a idéia de cidade-mercadoria (SANCHEZ, 1997), suprimindo, muita das vezes, a memória e os símbolos construídos ao longo do tempo, como vem ocorrendo com as feiras livres no Brasil.

Disseminando a idéia de "modernidade", as novas formas espaciais urbanas (CORRÊA, 2007) passam a copiar estilos arquitetônicos disformes das características locais, onde se busca uma padronização do espaço urbano. Nesse sentido, novos sistemas de ações (SANTOS, 2009a) passam a existir com esses espaços, proporcionando (ou não) a participação dos diferentes grupos sociais na produção do espaço urbano, como vem ocorrendo em São Bento com a construção do Mercado das Redes (Figura 3). A construção do Shopping e/ou Mercado das Redes, em São Bento, (espaço para onde será transferida a Feira da Pedra), está relacionada aos processos de construções e demolições das cidades contemporâneas, sejam elas pequenas, médias ou grandes, uma realidade das sociedades capitalistas, que constroem, reconstroem,

Geografia Ensino \& Pesquisa, v. 17, n.2 p. 39-56, mai./ago. 2013

Santos, J.E. 
num processo semelhante ao próprio sistema capitalista (HARVEY, 2005), o que se pode chamar, para o caso em discussão (o Shopping e/ou Mercado das Redes), de forma simbólica espacial (CORRÊA, 2007), ou seja, construção que o prefeito fez e cujo significado se constrói ao longo do tempo, cuja característica será os fluxos a serem desencadeados.

Figura 3 - São Bento (PB): vista geral do mercado ou shopping das redes

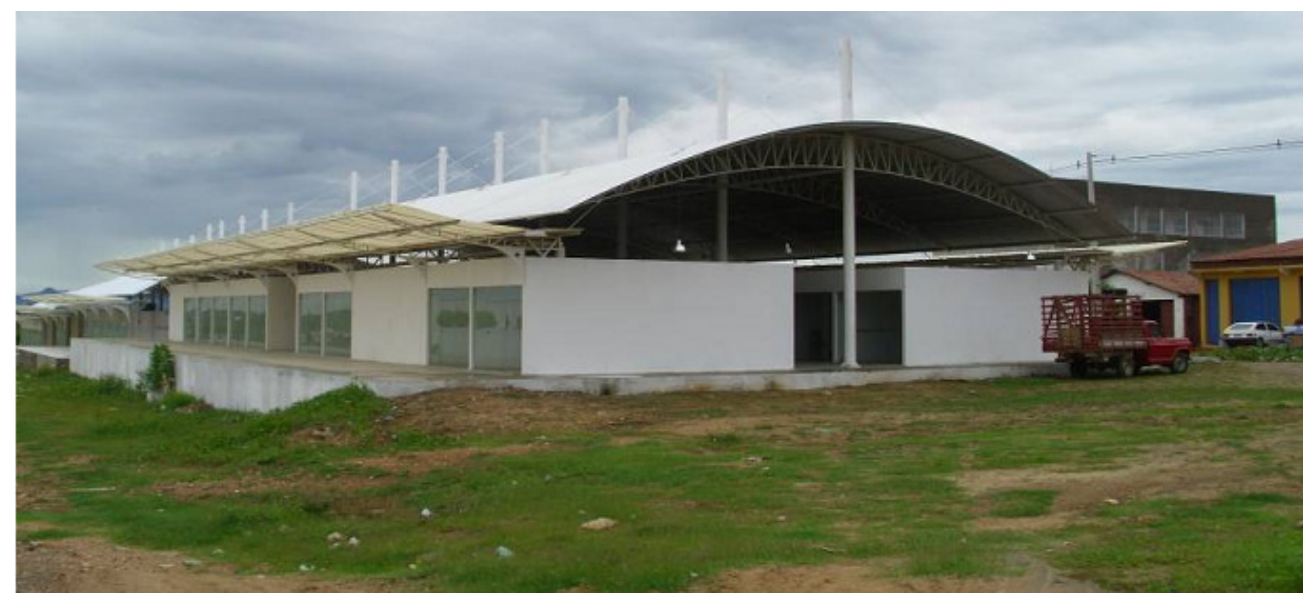

Fonte: Santos, (2012, p. 60).

Em suma, sobre o fato de ser a cidade um espaço de possibilidades, implica se refletir suas múltiplas condições de realizações que a caracteriza nesse período técnico-científicoinformacional. Ou seja, significa pensar a condição geopolítica que a cidade, neste período, desenha em relação aos seus territórios, uma vez que as possibilidades aí encontradas dependem de estratégias e/ou táticas voltadas para o controle e a apropriação de determinadas frações do sitio urbano (LEFEBVRE, 2001, CORRÊA, 1995). Dessa forma, o território emerge como elemento central de reivindicações (SANTOS, 2010). Não raro, as práticas sociais que permeiam o espaço urbano têm, nesse conceito chave da Geografia - o território -, um suporte material e, às vezes, imaterial (no caso de um território simbólico) para reivindicar o direito à cidade (LEFEBVRE, 2001; HAESBAERT, 2002).

4- Lembrando que redes aqui não no sentido de teia de relações estabelecidas entre os lugares, mas no sentido do objeto confeccionado para dormir, redes de dormir.

Geografia Ensino \& Pesquisa, v. 17 , n. 2 p. $39-56$, mai./ago..

Feiras Livres: (Re) Apropriação do território na/da cidade, neste período Técnico-CientíficoInformacional

Diante disso, a forma, a intensidade e a complexidade com que as disputas acontecem no espaço urbano são inerentes às relações de poder que aí são projetadas pelos diversos agentes produtores desse espaço. Assim, a partir do momento em que se constata a apropriação de frações do tecido urbano (como se pode ilustrar com o exemplo das feiras livres), mediante o estabelecimento de relações de poder, define-se, pois, um território (SOUZA, 1995).

Na cidade de São Bento, a principal característica é a fabricação de redes de dormir, fato que a torna denominada de Capital Mundial das Redes ${ }^{4}$. Em função disso, apresenta uma geografia peculiar em relação a outras cidades de mesmo tamanho no Estado da Paraíba. Possuindo mais de 300 pequenas, médias e grandes indústrias têxteis, que fabricam aproximadamente 600 mil redes ao mês, num processo que consome 12 milhões de $\mathrm{Kg}$ de fios por ano, em 1,2 mil teares que funcionam dia e noite para atender a demanda de consumo de vários estados brasileiros e também do exterior, como Bolívia, Paraguai etc., São Bento tem sua economia voltada para a fabricação de redes de dormir (CARNEIRO, 2006; HADDAD, 2004; MARTINS; VASCONCELOS; CÂNDIDO, 2007). Esse produto (a rede de dormir) apresenta grande diversificação de tipos e qualidades, sendo confeccionado tanto em grandes fábricas, como em pequenas tecelagens de fundo de quintal, espalhadas por todo o município. Baseado em fontes do IBGE, Haddad (2004) afirma que $80 \%$ da população economicamente ativa existente no município vive diretamente da produção, comercialização e distribuição de redes. 
Assim, a economia da cidade pauta-se em grande medida nas atividades ligadas à produção, ao comércio e aos serviços ligados a essa economia. Esta condição pressupõe pensar na forma pela qual os diferentes atores sociais lutam pela inclusão à lógica de seu funcionamento, cujo principal componente parece ser a apropriação e a definição de territórios, dos quais a Feira da Pedra é um deles.

Isso implica em afirmar que a existência da Feira da Pedra e também na cidade, sobretudo por ser realizada em via pública, tende a reforçar a luta pelo direito à cidade ou de, pelo menos, pequenas frações desse espaço.

O número total de feirantes-vendedores que "fazem" a Feira da Pedra é relativo no que concerne ao seu número durante as diversas épocas do ano. No início do ano, até aproximadamente o carnaval, esse número é o mais baixo, somando o total desses trabalhadores, aproximadamente 100. Do meio até o fim do ano, esse número pode chegar a ultrapassar os 130 feirantes-vendedores. Vale ressaltar que esses valores coincidem com os microterritórios, ou seja, com as áreas delimitadas por esses sujeitos socioespaciais em avenida e ruas do espaço urbano de São Bento, não sendo, nesse sentido, a somatória absoluta dos mesmos, no sentido de que em cada microterritório existem pelos menos de duas a três pessoas (geralmente da mesma família) comercializando produtos têxteis. Dessa forma, os atores sociais responsáveis pelo funcionamento e manutenção desses microterritórios, no caso os feirantes, representam uma parcela significativa da população compartilhando, semanalmente, estratégias coletivas na busca pela afirmação de suas intencionalidades.

De acordo com Foucault (2007), os poderes se organizam em formas locais e instantâneas, o que é característico nas feiras livres. Na Feira da Pedra é notório o poder, apresentando-se nos fragmentos de ruas e avenida da cidade, nas diferentes atividades parcelares que formam essa feira, cujo controle emana das lógicas do saber fazer, sendo o meio urbano atual, sobretudo nesse período técnico-científico-informacional, caracterizado por uma multiplicidade de pequenos microterritórios, cujas relações coletivas humanas acontecem numa rápida dinâmica no que diz respeito à construção e desconstrução de espaços de sobrevivência, de convivência e da transitoriedade dos indivíduos que participam de tais dinâmicas socioespaciais. Essas microterritorializações urbanas evidenciadas na Feira da Pedra aproximam indivíduos, uma vez que fundamentam concretamente formas e conteúdos e relações coletivas socioespaciais, fazendo com que durem certos processos entre feirantes-vendedores e feirantes-consumidores, em que, movidos por uma vontade frenética de experimentação e consumo de produtos têxteis diversos comercializados nesta feira, a vivificam/dinamizam, dando forma, função, processo e estrutura. Vale ressaltar ainda que o poder exercido nesses microterritórios se configura também a partir do ponto de vista simbólico, no sentido de: "poder quase mágico que permite obter o equivalente daquilo que é obtido pela força (física ou econômica), graças ao efeito específico de mobilização, [...] reconhecido, quer dizer ignorado como arbitrário (BOURDIEU, 2006, p. 14), já que existe um respeito e reconhecimento, por parte dos feirantes-vendedores, de cada canto (microterritório), como um subespaço do outro. Quando isso é transgredido têm-se conflitos, hostilidades e animosidades.

Nesse sentido, o trabalho exercido pelos feirantes expressa amplo sentido. Além de sua significativa importância econômica, uma vez que é elemento estruturador das relações de troca que permeiam esses microterritórios, esse mesmo trabalho pode ser entendido como um ato político, sendo seu reconhecimento, por parte dos demais atores socioespaciais produtores do espaço, fortalecedor dos laços entre o feirante e o seu "território de trabalho" - espaço delimitado nas ruas e avenida da cidade.

Reportando-se aos trabalhos de Jean Gottmann (1973; 2005), Saquet (2007, p. 27), afirma em seus estudos acerca do conceito de território e suas múltiplas formas de manifestações no âmbito do tecido socioespacial, o seguinte:

Geografia Ensino \& Pesquisa, v. 17, n.2 p. 39-56, mai./ago. 2013

Santos, J.E. 
5- Acredita-se que essa vertente da problemática que afeta as cidades brasileiras hoje, ou seja, essa massa de trabalhadores que não contribui diretamente com a previdência social e com a receita tributária da união, não se solucionará com essa medida, mas com uma racionalidade mais efetiva de desenvolvimento e efetivação de políticas públicas que levem em conta o trabalhador não somente

urbano, mas também o rural. A problemática que hoje afeta as cidades brasileiras, sobretudo as cidades maiores, resultam da formação econômica, social e, sobretudo, política do país.

Geografia Ensino \& Pesquisa, v. 17 , n. 2 p. $39-56$, mai./ago..

Feiras Livres: (Re) Apropriação do território na/da cidade, neste período Técnico-CientíficoInformacional e organização, ele tem duas funções principais: a) servir de abrigo, como forma de segurança e, b) servir como um trampolim para oportunidades. Segurança e oportunidade requerem uma organização interna do território bem como relações externas, de poder e dominação. Assim, o território assume distintos significados para diferentes sociedades e/ou grupos sociais dominantes.

Conforme já mencionado anteriormente, a construção de territórios na cidade implica em distintos conflitos, seja entre os grupos que territorializam o espaço, seja entre estes e o Estado, como acontece com as feiras livres. Isso porque o território é a expressão cabal das relações de poder travadas pelos diferentes atores sociais na produção do espaço urbano (SOUZA, 1995). No que se refere à Feira da Pedra e aos feirantes nela presentes percebe-se uma forte tendência a apropriação do território, mediante o estabelecimento do controle e do uso do espaço público (ruas e avenida da cidade de São Bento). Em outras palavras, a territorialização periódica dos feirantes manifesta a possibilidade da existência daqueles que fazem uso deste trabalho. Dessa forma, o território é desvelado como suporte material que permite a existência e o fortalecimento dos feirantes, no contexto de produção do espaço urbano.

Por fim, as feiras livres acontecem em distintos espaços e tempos e são um campo propício às reflexões geográficas. A presença da Feira da Pedra na cidade de São Bento, a exemplo das demais feiras livres espalhadas pelo país e Nordeste, reforça a ideia de que o trabalho do feirante só tem sentido quando essa ação se materializa no espaço; quando o coletivo, o grupo enquanto organização de suas ações se territorializam, fixando-se temporariamente em determinados locais. Dessa forma, sendo parte do circuito inferior da economia urbana de São Bento, impregnada de relações cotidianas mediante sua periodicidade de trocas comerciais, a Feira da Pedra (re)afirma o sentido e o significado que essa dimensão da economia citadina apresenta na conjuntura da cidade nesse período do espaço geográfico, cuja compreensão se faz melhor a partir do conceito de território, uma vez que este conceito geográfico configura-se como elemento geopolítico, em que o público passa a se confundir com o coletivo privatizado/territorializado, mediante as necessidades de (re)produção de um determinado grupo socioespacial - os feirantes.

\section{A Feira da Pedra e a gestão do território sãobentense}

Para Santos (1979, p. 129), "a intervenção do Estado na economia pode ser feita através dos investimentos". Nesta perspectiva, é importante tecer alguns comentários acerca da questão de um investimento verificado na cidade sede da feira em tela. Em outras palavras, passe-se a tecer algumas considerações acerca da ação do Estado (poder público municipal de São Bento), com a Feira da Pedra, no sentido de clarificar a relação Estado e feira livre, esta última apontada como parte do setor informal da economia urbana pelos gestores municipais e entendida neste trabalho como parte do circuito inferior da economia urbana dessa cidade.

Como é notório, há um interesse do Estado em tornar "formal” o que não é, levando em conta a economia urbana como uma totalidade sem estruturas (SANTOS, 2009b), pois se difunde a ideia de que, ao amparar e tornar essa massa de trabalhadores contribuinte da receita da união, é importante para o trabalhador e a sociedade como um todo, porque provoca o aumento da receita tributária. Em outras palavras, o Estado ver o circuito inferior como um setor informal que precisa ser formalizado ${ }^{5}$. Tal realidade vem ocorrendo em São Bento, com a construção do Shopping e/ou Mercado das Redes.

Isso decorre em função de na cidade, essas formas de controle e uso do espaço caracterizarem-se pela projeção das relações de poder, uma vez que a apropriação carrega um sentido, no qual está inscrito a intencionalidade (política) de sua ação. No caso da Feira da 
Pedra, a dinâmica imposta pelos feirantes que ali se estabeleceram, ainda na década de 1960, acabou sendo (re)produzida, automaticamente, nos anos seguintes por um grupo maior de trabalhadores, que nesse período técnico-científico-informacional são forçados a mudarem de local de trabalho: das ruas e avenida para um local fechado e com nova racionalidade.

A avenida Francisco de Paula Saldanha e o mercado/shopping das redes

A Avenida Francisco de Paula Saldanha, inicialmente teve um papel fundamental na consolidação das estratégias territoriais dos feirantes da Feira da Pedra, pois é lá que os feirantes desde há muito colocam suas mercadorias têxteis para serem comercializadas. Através dela pôde-se consolidar a instalação dos microterritórios e a posterior comercialização desses produtos.

De acordo com pesquisa de campo realizada na Feira da Pedra, pode-se inferir quatro fatores que influenciarão na dinâmica desses atores da referida feira, mediante a transposição desta para o Mercado das Redes: 1) a mudança de localização da feira; 2) a permissão municipal para se comercializar naquele local; 3) extinção do "trabalho informal" praticado pelos feirantes, que passará a ser configurado como "formal" e meio de sobrevivência "correto" na/da cidade; 4) necessidade de reconhecimento cada vez mais forte da cidade de São Bento enquanto Capital Mundial das Redes.

A localização geográfica é, sem dúvida, um fator de extrema importância e que justifica o enraizamento desses trabalhadores na referida feira, favorecendo dessa forma o acesso, tanto para os consumidores quanto para os fornecedores dos produtos têxteis que chegam à Feira da Pedra e nela territorializam espaços com maior facilidade.

Alega o poder público local de São Bento que no Mercado das Redes se configurará em um local permanente para o desenvolvimento do trabalho do feirante, podendo fazer isso de forma diária e não apenas semanalmente como ocorre na Feira da Pedra. Dessa forma, o Mercado das Redes será o local para onde se destinará a Feira da Pedra, em fase de acabamento, idealização do poder público municipal, trajada de política pública que, segundo informações dessa instância governamental, irá melhorar a vida dos feirantes, tirando-os do espaço a céu aberto e os alocando em um local digno de comercialização, mais organizado e com condições melhores para a realização desse comércio, que se entende neste trabalho como uma estratégia do poder público local no sentido da alternativa para administrar os conflitos na cidade, diante da competição e mobilidade na mesma (CAMPOS JÚNIOR, 2000; VALVERDE, 2004). Assim, exportando redes de dormir e demais produtos têxteis para todos os estados brasileiros e para países da América do Sul, São Bento assumiu uma posição privilegiada no ranking da economia regional, sendo a construção desse fixo o reforço cada vez maior da marca dessa atividade na cidade.

Se se fizer uma arqueologia da relação poder público municipal e feira livre, na história, percebe-se que essa relação é repleta de tensões. Para citar um exemplo, basta mencionar os trabalhos de Jesus (1992; 2009).

Jesus (1992, p. 95) mostra que a feira livre carioca já foi "responsável pela distribuição da maior parte dos hortigranjeiros, frutas e pescado consumidos diariamente pela população carioca, superando nestes setores todas as demais formas de varejo somadas: supermercados, quitandas, peixarias [...]". Segundo esse autor, a importância dessa forma de comércio começa a ser comprometida quando, a partir dos anos 1950, começam a surgir "[...] os supermercados, um grande adversário para as feiras no varejo da cidade", ocupando o espaço urbano carioca mediante incentivos do governo local. Inserindo-se no circuito superior ${ }^{6}$ da economia urbana, os supermercados logo começaram, não somente na cidade analisada por esse autor, a ganharem os prestígios e apoios governamentais, mas também se expandirem "rapidamente, formando
6- O circuito superior referese ao conjunto de atividades realizadas com capital intensivo, resultado direto da modernização tecnológica, cuja maior parte das relações ocorre fora da cidade, uma vez que possui referência nacional e internacional. Nesta categoria de produção, comércio e consumo enquadram-se os bancos, as indústrias, os serviços modernos, atacadistas e transportadores.

Geografia Ensino \& Pesquisa, v. 17, n.2 p. 39-56, mai./ago. 2013

Santos, J.E. 
7- O circuito inferior consiste de atividades em pequenas escalas e são praticadas pela parcela da população que não tem acesso às atividades econômicas do circuito superior, por falta de "qualificação profissional", segundo a massa capitalista dominante, configurando-se de forma "primitiva" do ponto de vista organizacional. São

exemplos as atividades da economia informal praticadas por ambulantes, carregadores e pequenos comércios, os denominados pobres. Para Santos (1979), contrariamente ao circuito superior, o inferior é bem sedimentado e goza de relações privilegiadas com sua

Geografia Ensino \& Pesquisa, v. 17 , n.2 p. 39-56, mai./ago..

Feiras Livres: (Re) Apropriação do território na/da cidade, neste período Técnico-CientíficoInformacional extensas redes que atuam a nível nacional e até internacional [...]” (JESUS, 1992, p. 96). Diante disso, o referido autor discute a relação da feira carioca frente às modernizações, ocorridas na "cidade maravilhosa" no século passado, cunhadas tanto pelos agentes econômicos (donos de supermercados), quanto pelos políticos, mostrando suas estratégias e fatores que a levou a permanecer na economia urbana dessa cidade.

Em seu trabalho posterior sobre negociação dos usos e sentidos da rua, em que enfoca a trajetória e as representações da feira livre carioca, esse autor afirma que:

Em diferentes momentos, verificamos que o Poder Público investe sobre a sociabilidade das ruas, no sentido de impor interesses dominantes. Para intervir com autoridade, produz um discurso 'competente', que num primeiro momento cria e idolatra a feira livre, importação européia, para mais adiante a perseguir, como território de ilegalidades, atraso, sujeira, desordem (JESUS, 2009, p. 162).

Neste mesmo trabalho, o referido autor mostra que o declínio dessa atividade de comércio periódico se acentua com as modernizações, sobretudo na área de transporte que necessita, dentro do tecido urbano, de vias de circulação mais apropriadas, retirando delas os sujeitos que a usavam como local de sobrevivência, sobretudo por meio da atividade feira livre.

O Shopping e/ou Mercado das Redes é, pois, um novo elemento da paisagem urbana são-bentense, construído para finalidade social daqueles sujeitos comerciantes, tirando-os das ruas e avenida e os alocando-os em um local "apropriado de comercialização", bem como servindo, também, para angariar impostos daqueles trabalhadores que vivem da atividade de feirante, apontados como trabalhadores informais. Um local que seja capaz de reunir os feirantes têxteis que, ao longo do tempo, sempre se aglutinaram nas proximidades da Igreja Matriz de São Sebastião, localizada no centro da cidade, irá angariar tributos ao cofre público local, já que o funcionamento da Feira da Pedra não demanda cobrança de tributos por parte da prefeitura local.

A construção dessa forma simbólica espacial e o possível deslocamento da Feira da Pedra para o seu interior reordenará, de certa maneira, a dinâmica do espaço urbano sãobentense, sobretudo na periodicidade com que essa feira ocorre. Sendo a Feira da Pedra um lugar de comércio e sociabilidade que ajuda a manter viva a cultura local e regional, as tradições e também as crenças do imaginário dos sujeitos que a ela se ligam mediante o advento dessa forma simbólica espacial pode romper/separar a cidade do seu passado, uma vez que a inserção dessa feira, nesse novo espaço, passará a se classificar também como uma manifestação da modernidade. Assim, a Feira da Pedra representa um importante papel na distribuição de produtos têxteis e fonte de diferentes tipos de ofícios individuais que asseguram a sobrevivência de muitos nordestinos. Com o estabelecimento de seu deslocamento futuro para o Shopping e/ou Mercado das Redes serão muitos os efeitos, sobretudo sociais, pois "o comportamento do espaço depende tanto das ações passadas como das ações atuais" (SANTOS, 2008b, p. 232).

Dessas ressalvas, pode-se afirmar que São Bento, como todas as cidades, nesse período técnico-científico-informacional, metamorfoseia-se. O comportamento social na era da globalização-fragmentação encontra-se em plena efervescência. Nisso, novos hábitos e novos gostos se expressam nas maneiras de morar, de trabalhar, no sistema de objetos e no sistema de ações que organiza os espaços (SANTOS, 2009a). A sociedade abandona, definitivamente, as velhas formas de viver baseadas na labuta tradicional, caminhando para um novo estilo de vida mais pautado no convívio público social, cuja racionalidade é aquela ditada pelo mercado e pelo Estado, ou seja, na ação estratégica (HABERMAS, 2001), muito embora dentro de um circuito inferior ${ }^{7}$.

De acordo com o diagnóstico desse último autor, o processo de racionalização, 
fundador da modernidade, a razão técnico-instrumental predomina nas esferas sistêmicas correspondentes ao Estado e também ao Mercado, que é regida ou comandada por princípios, respectivamente, do poder e do dinheiro. $\mathrm{Na}$ atualidade, esses princípios autonomizaram-se ao ponto de ultrapassarem os seus limites, invadindo a esfera comunitária do "mundo de la vida" (HABERMAS, 2001, p. 10), cujas relações de socialização, de solidariedade e de reprodução cultural, através da comunicação livre entre as pessoas, que levam ao consenso, são afetadas pelos interesses dominantes da Política e da Economia (HABERMAS, 2001).

Ademais, nesse período técnico científico-informacional, ao invés do Estado buscar perseguir o que concebe por informalidade, deveria, em partes, partir para uma necessidade, aquela apontada por Maria do Livramento M. Clementino: "necessidade de que os governos locais, em conjunto com entidades da sociedade civil, interfiram na dinâmica econômica e construam projetos capazes de gerar um maior dinamismo das atividades econômicas e maior redistribuição da riqueza e da renda" (CLEMENTINO, 2002, p. 122), e não buscar mecanismos que os levem à extinção de condições materiais de existência de cidadãos. Muito embora saibamos das dificuldades "para absorver a totalidade das pessoas que comparecem ao mercado" (CLEMENTINO, 2002, p. 127), isso deve estar na pauta dos governos, nesse meio e período técnico.

A construção do Mercado das Redes cogita insatisfações por parte dos feirantes da Feira da Pedra, uma vez que, segundo os mesmos, essa forma simbólica espacial irá beneficiar apenas alguns deles, deixando muitos comerciantes fora do seu "abrigo", sobretudo os provenientes de outras municipalidades. A esse respeito se indaga: Qual dinâmica se configurará à Feira da Pedra com sua transferência para este local? Qual será o impacto na vida dos sertanejos que sobrevivem dessa atividade, direta e indiretamente? Nota-se, assim a nítida preocupação dos feirantes quando indagados sobre a transposição da feira, pois em ressaltarem suas histórias de vida, percebe-se que ela se confunde com a sua luta permanente à busca pelo direito à sobrevivência. A sua única opção de trabalho o empurrou para o circuito inferior da economia e através dele pode consolidar um sentido de apropriação do espaço público, no qual o trabalho "informal" permitiu a manutenção de sua territorialidade.

Pode-se afirmar que a tradição da comercialização dos produtos têxteis feita em ruas e avenida de São Bento (na Feira da Pedra) se organizará a partir das rédeas mais intenta do governo local, cuja materialidade espacial se configurará numa racionalidade pautada nos interesses exclusivos do Mercado e do Estado, sobretudo para atender às necessidades, de certa forma, extra local, pois o Mercado das Redes se configurará num ícone que funcionará com dinamicidade permanente e não periódica, como é a feira, atraindo turistas que frequentem, por ventura, a região e o local.

No entanto, como se nota em outros locais de feira, a Feira da Pedra recebeu um grande contingente de pessoas que se lançam na vida de feirante, nesse período técnicocientífico-informacional, sobretudo do final dos anos 1980 e início dos anos 2011. Isso se deve à instabilidade econômica e social do país, com reflexos diretos no mercado de trabalho local, uma vez que se vive uma economia globalizada, sendo a rua, nesse caso, a saída emergencial encontrada por grande parte dessas pessoas, e a feira, um espaço privilegiado.

A presença marcante do circuito inferior da economia na Feira da Pedra e em particular na cidade de São Bento, não apenas ratifica sua importância na configuração econômica dessa cidade nordestina, mas fornece os elementos imprescindíveis à luta pela cidade ou de pelo menos de certas frações dela, como é o caso da Feira da Pedra. Por isso, Santos (1979, p. 33) é enfático quando afirma que no "circuito inferior, a tecnologia é o trabalho intensivo e frequentemente local ou localmente adaptada ou recriada".

A Feira da Pedra desempenha uma importância não apenas no âmbito local, mas também em nível regional, no que diz respeito aos serviços gerados e aos produtos comercializados.

Localmente, ao ar livre, é comercializada grande parte dos produtos têxteis fabricados
8- Para Habermas, o mundo da vida é "[...] un mundo compartido por todos" (HABERMAS, 2001, p. 31). Exemplo disso é a própria Feira da Pedra, na medida em que relações de afetividade e solidariedade são compartilhadas pelos feirantes-vendedores, embora de forma territorial.
Geografia Ensino \& Pesquisa, v. 17, n.2 p. 39-56, mai./ago. 2013

Santos, J.E. 
9 É sabido que, quando são pensadas propostas urbanísticas para a cidade, apenas uma pequena parcela da população desfruta das condições produzidas por

tais propostas. Não será diferente em São Bento com o Mercado/Shopping das Redes.

Geografia Ensino \& Pesquisa, v. 17 , n. 2 p. $39-56$, mai./ago.

Feiras Livres: (Re) Apropriação do território na/da cidade, neste período Técnico-CientíficoInformacional ISSN 2236-4994 em São Bento, produtos estes fabricados pelos pequenos, médios e grandes produtores têxteis locais, que veem nesta feira uma oportunidade de comercializarem suas mercadorias, aumentando assim o mercado dos seus produtos.

Regionalmente, sua importância advém do fato de os produtores de artigos têxteis das demais cidades da região, tanto do Sertão Paraibano quanto do Seridó Potiguar, venderem seus produtos têxteis neste sistema de comércio urbano, disputando o mercado local, conforme já percebeu Carneiro (2006).

Diante disso, a transposição dessa atividade para outro local, agora com uma nova racionalidade, não pode ser analisada tão somente por um aspecto, mas também e, acima de tudo, pelas intencionalidades, no sentido de se identificar que tipos de interesses (público e privado), (público e coletivo), concorreram nessa prática socioespacial quando a ela é dada uma nova racionalidade.

Os feirantes que ocupam as ruas e avenida para vender os produtos têxteis passarão a trabalhar na nova estrutura arquitetônica da feira - o Mercado/Shopping das Redes. A realização desta atividade adotará o sistema de auto-gestão tendo como suporte o controle da prefeitura de São Bento. Como hipótese pode-se afirmar que os feirantes que a este espaço ocupará passarão por novas racionalidades ditadas pelo governo local e o mercado econômico, tal qual já ocorreu com aqueles trabalhadores feirantes de Santa Cruz do Capibaribe (PE), hoje ocupantes do Santa Cruz Moda Center, cuja racionalidade predominante é a padronização dos locais de venda dos mesmos.

Nesse sentido, a presença de outros elementos marcando a sociabilidade entre esses sujeitos socioespaciais como é o caso da padronização dos mesmos, pressupõe-se novas dinâmicas à atividade feira, cujas regras de conduta e comportamento são as expressões maiores. Não restam dúvidas que a padronização da Feira da Pedra acarretará na melhoria das condições de comercialização para uma parte ${ }^{9}$ dos feirantes daquela feira, bem como urbanismo do local. No entanto, implicará em novas formas de gestão do território, pois os feirantes passarão a ser reconhecidos como os responsáveis pela manutenção do novo local - o Mercado/Shopping das Redes, mediante arrecadação de tributos cobrados pelo Estado a esses sujeitos socioespaciais.

Por fim, pode-se afirmar que esta nova forma de gerir os espaços públicos, sobretudos os espaços de apropriação coletiva, como é o caso das feiras livres, em específico a Feira da Pedra, obedece aos ditames do período e meio técnico-científico-informacional, cuja reafirmação do Estado enquanto "promotor do bem comum" e, do mercado econômico (economia), por outro, coloca em evidência as questões que envolvem o território urbano, pondo em relevo os grupos socioespaciais mais excluídos do circuito inferior da economia urbana, onde a competitividade na/da vida urbana é o ponto de entendimento desse processo.

Em São Bento, o novo espaço e/ou território da Feira da Pedra pode significar a quebra desta tradicional atividade socioespacial econômica e cultural daquela cidade paraibana, muito embora ela apresente em sua paisagem e estrutura, forma função e processo distintos níveis, pois a simbiose entre o "moderno" e o "tradicional", é uma realidade, muito embora prevalecendo este último aspecto, o a caracteriza como um segmento mais inserido no circuito inferior da economia urbana, dadas as características que apresenta em sua forma: trabalho intensivo, mão-de-obra familiar, pouco estoque, etc. A comercialização exclusiva de produtos têxteis locais e regionais nessa feira, bem como ainda as tecituras de sociabilidades nela percebidas são elementos de distinção das outras feiras. Nesse período e meio técnicocientífico-informacional, com as recentes políticas públicas voltadas a padronização dos espaços urbanos e dentro deles o espaço das feiras livres, é notório que o tradicional só possa passa a (co)existir com o moderno, no sentido de fazer surgir novas práticas cotidianas, cujo marco são as disputas que revelam o território da vida de cada dia no espaço urbano. 


\section{Considerações finais}

O objetivo deste artigo foi refletir sobre feira livre, enfatizando sua importância na contemporaneidade dentro do/no espaço citadino, que se apresenta cada vez mais competitivo e fragmentado, cujo centro das discussões não poderiam girar fora do ponto de vista da (re) apropriação do território.

A expansão e consolidação do período e meio técnico-científico-informacional que configura os circuitos da economia urbana, dando ao circuito inferior uma capacidade cada vez mais intensa de se tornar o abrigo e proteção de grande massa da população citadina que não tem acesso ao circuito superior, fazendo com que a atividade feira livre, a exemplo da Feira da Pedra se tornasse um espaço propício à manutenção da vida cotidiana de muitos sujeitos socioespaciais nesse período.

Esse período do espaço geográfico trouxe também a necessidade por parte do Estado afastar das áreas centrais a atividade feira livre, como se pôde perceber em são Bento, não sendo mais a visão econômica suficiente para entender e explicar a complexidade que está camuflada na dinâmica de funcionamento dessa atividade, uma vez que é necessário entender o que se passa nas relações que só a utilização dos elementos do conceito de território podem dar: as relações de poder que existem no espaço urbano, que envolvem grupos socioespaciais diversos. Dessa forma, na atividade feira livre é sabido do seu conteúdo de modos de vida, que mediante relações dialéticas se contrapõem e também reforçam a racionalidade de estruturação do espaço citadino, sendo a reflexão por parte do conceito de território fundamental ao entendimento desse processo.

É inegável, como se pôde perceber a partir da Feira da Pedra, que a atividade feira livre carregue em sua realização estratégias de controle do território. Os feirantes se organizando em grupos socioespaciais, são sujeitos que (re)produzem o espaço urbano. Fazem isso através da apropriação de determinados fragmentos do espaço público citadino periodicamente, o que na perspectiva territorial é rico de relações geopolíticas, travadas entre feirantes e poder público municipal.

Em suma, as feiras livres de uma maneira geral e, em específico a Feira da Pedra, quando analisadas no contexto da (re)produção do espaço urbano, expressam aquilo que Santos (2009a) afirmou para o caso do espaço geográfico: a contraposição entre a solidariedade orgânica e solidariedade organizacional, sendo a primeira típica dos feirantes e, a segunda, do Estado e do mercado econômico e o seu entendimento não pode passar fora dessa realidade.

\section{Referências bibliográficas}

ANDRADE, M. C. de. A terra e o homem no Nordeste: contribuição ao estudo da questão agrária no Nordeste. 5. ed. São Paulo: Atlas, 1986.

ANDRADE, M. C. de. Geografia Econômica do Nordeste: o espaço e a economia nordestina. 4. ed. São Paulo: Atlas, 1987.

BOURDIEU, P. O poder simbólico. 9. ed. Rio de Janeiro: Bertrand Brasil, 2006.

BRAUDEL, F. Civilização material, economia e capitalismo: séculos XV-XVIII. (Tradução Telma Costa). Vol. 2. São Paulo: Martins Fontes, 1996.

CAMPOS JÚNIOR, C. T. de. A Diferença como Alternativa para Administrar os Conflitos nas Cidades. Geografares. Vitória, v.1, nº 1, jun. 2000. p 21-27.

CARLOS, A. F. A. A Construção de uma "nova urbanidade". In: SILVA, J. B. da. et.al. (orgs.).

Geografia Ensino \& Pesquisa, v. 17, n.2 p. 39-56, mai./ago. 2013

Santos, J.E. 
A cidade e o Urbano: Temas para debates. Fortaleza: EUFC, 1997. p. 199-212.

CARNEIRO, R. N. Produção do espaço e circuitos de fluxos da indústria têxtil de São Bento-PB: do meio técnico ao meio técnico-científico-informacional. 2006. 185 f. Dissertação (Mestrado em Geografia) - Centro de Filosofia e Ciências Humanas, Universidade Federal de Pernambuco, Recife, 2006.

CASCUDO, L. da C. Rede de dormir: uma pesquisa etnográfica. 2. ed. São Paulo: Global, 2003.

CLEMENTINO, M. do L. M. Políticas públicas e formação econômica das cidades. In: VALENÇA, M. M.; GOMES, R. de C. da C. (Orgs.). Globalização e desigualdade. Natal: A. S. Editores, 2002.

CORREAA, R. L. Formas simbólicas e espaço: algumas considerações. GEOgraphya. Ano IX; n. 17, 2007.

CORRÊA, R. L. O Espaço Urbano. 3. ed. São Paulo: Ática, 1995. (Série Princípios).

CORREAA, R. L. Trajetórias geográficas. 2. ed. Rio de Janeiro: Bertrand Brasil, 2001.

DEFFONTAINES, P. As feiras de burros de Sorocaba. Boletim Geográfico. Ano 3, nº 25. Rio de Janeiro: IBGE, 1945. p. 42-45.

FOUCAULT, M. Microfísica do poder. 23 ed. Rio de Janeiro: Edições Graal, 2007.

Guimarães, O. O papel das feiras-livres no abastecimento da cidade de São Paulo. São Paulo: Instituto de Geografia/ USP, 1969. (Série Teses e Monografias, n.2).

HABERMAS, J. Teoría de la acción comunicativa: racionalidad de la acción y racionalización social. 4. ed. Madrid: Taurus, 2001. vol. 1.

HADDAD, P. R. APL - São Bento: cultura local e associativismo. 2004. Disponível em: $<$ www.bndes.gov.br/SiteBNDES/.../bndes.../conhecimento/seminario/apl22.pdf>. Acesso em: 09 fev. 2011.

HAESBAERT, R. Territórios Alternativos. Niterói: EDUFF. 2002.

HARVEY, D. A produção capitalista do espaço. São Paulo: Annablume, 2005.

JESUS, G. M. de. Negociando os usos e sentidos da rua: trajetória e representações da feira livre carioca. In: CARRERAS, C.; PACHECO, S. M. M. (Orgs.). Cidade e comércio: a rua comercial na perspectiva internacional. Rio de Janeiro: Armazém das Letras, 2009.

Geografia Ensino \& Pesquisa, v. 17, n. 2 p. $39-56$, mai./ago..

2013

Feiras Livres: (Re) Apropriação do território na/da cidade, neste período Técnico-CientíficoInformacional de. O lugar da feira livre na grande cidade capitalista: Rio de Janeiro, 1964-1989.

Revista Brasileira de Geografia/Fundação Instituto Brasileiro de Geografia e Estatística, Rio de Janeiro, ano I, n. 1, p. 95-120, jan./mar., 1992.

LEFEBVRE, H. O Direito à Cidade. Tradução; Rubens Eduardo Frias. $2^{a}$ ed. São Paulo: Centauro, 2001.

MARTINS, M. de F.; VASCONCELOS, A. C. F.; CÂNDIDO, G. A. A contribuição da gestão ambiental para o desenvolvimento e competitividade do APL têxtil de São Bento-PB. In: ENCONTRO NACIONAL SOBRE GESTÃO EMPRESARIAL E MEIO AMBIENTE/ ENGEMA, 09., 2007, Curitiba. Anais... Curitiba, 2007. 
MOTT, L. R. de B. A feira de Brejo Grande: estudo de uma instituição econômica num município sergipano do Baixo São Francisco. 1975. 348 f. Tese (Doutorado em Ciências Sociais) - Universidade de Campinas, Campinas-SP, 1975.

MUMFORD, L. A cidade na história: suas origens, transformações e perspectivas. 4. ed. São Paulo: Martins Fontes, 1998.

PAZERA JR, E. A Feira de Itabaiana-PB: permanência e mudança. 2003. 201 f. Tese (Doutorado em Geografia) - Faculdade de Filosofia, Letras e Ciências Humanas, Universidade de São Paulo, São Paulo, 2003.

SANCHEZ, F. Cidade Espetáculo: política, planejamento e city marketing. Curitiba: Palavra, 1997.

SANTOS, J. E. Feira livre e circuitos da economia urbana: um estudo da Feira da Pedra, em São Bento (PB). Natal, 2012. 294 f. Dissertação (Mestrado em Geografia) - Universidade Federal do Rio Grande do Norte, 2012.

SANTOS, M. O espaço dividido: os dois circuitos da economia urbana dos países subdesenvolvidos. Rio de Janeiro: Francisco Alves, 1979. (Ciências sociais).

A urbanização Brasileira. 2. ed. São Paulo: HUCITEC, 1994. (Estudos urbanos; 5).

SANTOS, M.; SILVEIRA, M. L. O Brasil: território e sociedade no início do século XXI. 4. ed. Rio de Janeiro: Record, 2002.

SANTOS, M. Da totalidade ao lugar. São Paulo: Edusp, 2005.

Técnica, espaço, tempo: globalização e meio técnico-científico informacional. 5. ed. São Paulo: Edusp, 2008a . (Coleção Milton Santos; 11).

Por uma geografia nova: da crítica da geografia a uma geografia crítica. 6. ed. $1^{\mathrm{a}}$ reimpr. São Paulo: Edusp, 2008b. (Coleção Milton Santos; 2).

A natureza do espaço: técnica e tempo, razão e emoção. 4. ed. 5. reimpr. São Paulo: Edusp, 2009a. (Coleção Milton Santos; 1).

Pobreza urbana. 3. ed. São Paulo: Edusp, 2009b. (Coleção Milton Santos; 16).

Por uma outra globalização: do pensamento único a consciência universal. 19. ed. Rio de Janeiro: Record, 2010.

SAQUET, M. A. Abordagens e concepções de território. São Paulo. Expressão Popular, 2007.

SENA, A. L. Trabalho Informal nas Ruas e Praças de Belém. Belém: NAEA, 2002.

SOUZA, M. J. L. de. O Território. Sobre espaço e poder, autonomia e desenvolvimento. In: CASTRO, I. E. et al. (orgs.). Geografia: conceitos e temas. Rio de Janeiro: Bertrand Brasil, 1995. p. 77-116.

TRINDADE JR. S. C. da. Agentes, redes e territorialidades urbanas. Revista Território, $\mathrm{n}^{\circ}$ 5 - Jul/ Dez. LAGET/UFRJ, 1998. p. 31-50.

Geografia Ensino \& Pesquisa, v. 17, n.2 p. 39-56, mai./ago. 2013

Santos, J.E. 
na Cidade. GEOUSP - Espaço e Tempo, São Paulo, nº 15, 2004. p. 119-126.

\section{Correspondência:}

José Erimar dos Santos - Rua Francisco dos Santos Aquino, nº. 15, Chã, Serrinha dos Pintos/ $\mathrm{RN}$.

E-mail: zerieval@yahoo.com.br

Recebido em 08 de junho de 2012.

Revisado pelo autor em 06 de março de 2013.

Aceito para publicação em 10 de setembro de 2013.

Geografia Ensino \& Pesquisa, v. 17 , n.2 p. 39-56, mai./ago..

Feiras Livres: (Re) Apropriação do território na/da cidade, neste período Técnico-CientíficoInformacional 